\title{
Article
}

\section{A new species in the Skeletocutis subincarnata complex (Polyporales, Basidiomycota) from southwestern China}

\author{
Fan LF, Ji XH and Si J \\ Institute of Microbiology, P.O. Box 61, Beijing Forestry University, Beijing 100083, China
}

Fan LF, Ji XH, Si J 2017 - A new species in the Skeletocutis subincarnata complex (Polyporales, Basidiomycota) from southwestern China. Mycosphere 8(6), 1253-1260, Doi 10.5943/mycosphere/8/6/10

\begin{abstract}
A new polypore species, Skeletocutis pseudo-odora, was collected on fallen branches of Pinus armandii in Guizhou Province, southwestern China. It is described based on molecular data and morphological characteristics. The species belongs to the Skeletocutis subincarnata complex, and macro-morphologically resembles $S$. albocream and microscopically is similar to Skeletocutis odora. However, $S$. albocream can be readily distinguished from $S$. pseudo-odora by having hyphal pegs and wider basidiospores $(4-5 \times 1.3-1.7 \mu \mathrm{m})$. S. pseudo-odora differs from S. odora in having corky basidiocarps without any odour or taste when fresh, smaller pores (6-8 per $\mathrm{mm}$ ), thick and entire dissepiments. Phylogeny inferred from the ITS dataset indicates that Skeletocutis under the current concept was not a monophyletic genus and S. pseudo-odora was distinct from other sampled species of Skeletocutis, including S. odora.
\end{abstract}

Key words - Phylogeny - polypore - taxonomy - wood-decaying

\section{Introduction}

The polypore genus Skeletocutis Kotl. \& Pouzar, typified by Skeletocutis amorpha (Fr.) Kotl. \& Pouzar, was established in 1958 (Kotlába \& Pouzar 1958). Species of the genus mostly have resupinate basidiocarps although its type species has pileate or effused-reflexed basidiocarp, many species have tiny basidiospores and are found on gymnosperm wood in boreal and temperate forests from the northern hemisphere (Gilbertson \& Ryvarden 1987, Niemelä 1998, Dai 2002, Dai \& Wu 2004, Dai 2012, Ryvarden \& Melo 2014, Bian et al. 2016). During the survey of lignicolous fungi in southwestern China, four specimens were collected on fallen branches of Pinus armandii from Leigongshan Nature Reserve, Guizhou Province, and they have resupinate basidiocarps with distinct cottony sterile margin, small pores, a dimitic hyphal structure with scanty skeletal hyphae at dissepiment edges, tramal generative hyphae bearing fine, sharp-pointed encrustations, and allantoid basidiospores. These characters make these collections to represent a taxon in the Skeletocutis subincarnata complex, but no suitable existing name is available for them. After phylogenetic analysis and morphological examination, they turn out to be an undescribed species, and here we describe them as new.

\section{Materials \& Methods}

\section{Morphological studies}


The studied specimens are deposited in the herbarium of the Institute of Microbiology, Beijing Forestry University (BJFC). The microscopic procedure follows Dai (2010). Microscopic measurements were made from slide preparations stained with Cotton Blue, Melzer's reagent and $5 \%$ potassium hydroxide. In the text the following abbreviations were used: $\mathrm{KOH}=5 \%$ potassium hydroxide, IKI $=$ Melzer's reagent, IKI $-=$ neither amyloid nor dextrinoid, $\mathrm{CB}=\mathrm{Cotton}$ Blue, $\mathrm{CB}-$ = cyanophilous, $\mathrm{L}=$ mean spore length (arithmetic average of all spores) $\mathrm{W}=$ mean spore width (arithmetic average of all spores), $\mathrm{Q}=$ variation in the ratios of $\mathrm{L} / \mathrm{W}$ between specimens studied, $\mathrm{n}$ $=$ number of spores measured from given number of specimens. Colour terms followed Petersen (1996).

\section{Molecular procedures and phylogenetic analyses}

The methods of DNA extraction and amplification in this study followed Chen et al. (2016). CTAB rapid plant genome extraction kit-DN14 (Aidlab Biotechnologies Co., Ltd, Beijing) was used to extract total genomic DNA from dried specimens of the new collections according to the manufacturer's instructions with some modifications. The primers ITS5 /ITS4 was used for PCR amplifications (primer sequences used in this study were obtained from http://www.biology.duke.edu/fungi/mycolab/primers.htm). The PCR products were sequenced in Beijing Genomics Institute, China, with the same primers. The newly generated sequences were deposited at GenBank and labelled in Fig. 1.

Besides the newly generated ITS sequences, the current ITS dataset included sequences from all available species of the three genera, viz. Piloporia, Skeletocutis and Tyromyces, in the tyromyces clade (Binder et al. 2013). The ITS sequences of Cinereomyces lindbladii from the gelatoporia clade was selected as outgroup (Binder et al. 2013). This dataset was aligned using MAFFT 7.110 (Katoh \& Standley 2013) with the Q-INS-I opinion (Katoh et al. 2005).

Maximum likelihood (ML) and maximum parsimony (MP) were used to perform phylogenetic analysis. ML analysis was conducted using raxmlGUI 1.2 (Stamatakis 2006, Silvestro \& Michalak 2012) under GTR + I + G evolutionary model. Bootstrap (BS) values were calculated under the auto FC option (Pattengale et al. 2010). MP tree was constructed using PAUP* version $4.0 \mathrm{~b} 10$ (Swofford 2002) with the heuristic search option and default parameters. All characters were equally weighted and gaps were treated as missing data. Clade robustness was assessed using a BS analysis with 1,000 replicates (Felsenstein 1985).

\section{Results}

\section{Phylogeny}

The ITS dataset, including 26 sequences, resulted in an alignment with 784 characters, of which 396 characters are constant, 112 parsimony-uninformative and 276 parsimony-informative. BS searches for the ML analysis stopped after 350 replicates. MP analysis yielded six equally parsimonious trees $(\mathrm{CI}=0.557, \mathrm{RI}=0.601)$. The $\mathrm{ML}$ and MP analyses generated congruent topologies in main clades, and thus only that from ML analysis was presented with BS values from both analyses.

The ITS-based phylogeny indicated the monophyly of either Skeletocutis or Tyromyces is questionable (Fig. 1). The newly sequenced specimens formed a distinct lineage (97\% in ML, $100 \%$ in MP) from other sampled species.

\section{Taxonomy}

Skeletocutis pseudo-odora L.F. Fan \& Jing Si, sp. nov.

Index Fungorum number: IF553635; Facesoffungi number: FoF02916

Type - CHINA, Guizhou Province, Leishan County, Leigongshan Nature Reserve, on fallen branch of Pinus armandii, alt, 1800 m, 13 June 2016, Yu-Cheng Dai 16525 (Holotype, BJFC022513)

Etymology - Pseudo-odora (Lat.): referring to the similarity to Skeletocutis odora. 




Fig.1 - Phylogenetic position of Skeletocutis pseudo-odora inferred from the ITS dataset. The topology resulted from the maximum likelihood analysis is presented with bootstrap values from maximum likelihood (before the slash) and maximum parsimony (after the slash) analyses, if simultaneously higher than $50 \%$, at the nodes. The newly sequenced specimens are labeled in boldface

Fruitbody - Basidiocarps annual, resupinate, very difficult to separate from substrate, soft leathery and without odour or taste when fresh, becoming hard corky upon drying, up to $6 \mathrm{~cm}$ long, $1.8 \mathrm{~cm}$ wide, and $1 \mathrm{~mm}$ thick at centre. Pore surface snow white to white when fresh, brownish buff and sometimes cracked upon drying; margin distinct, consistent white, byssoid to cottony, up to 2 $\mathrm{mm}$; pores round, freely arranged, 6-8 per mm; dissepiments thick, entire. Subiculum white, soft corky, very thin, less than $0.1 \mathrm{~mm}$ thick. Tubes concolorous with poroid surface, hard corky, up to $0.9 \mathrm{~mm}$ long.

Hyphal structure - Hyphal system dimitic, generative hyphae with clamp connections, hyaline, thin-walled, dominant at dissepiment edge; skeletal hyphae thick-walled with a narrow lumen to subsolid; all hyphae IKI-, $\mathrm{CB}-$, unchanged in $\mathrm{KOH}$.

Subiculum - Generative hyphae frequent, hyaline, thin-walled, smooth, occasionally branched and smooth, 2.5-3.5 $\mu \mathrm{m}$ diam; skeletal hyphae dominant, thick-walled, flexuous, unbranched, interwoven, 3-4 $\mu \mathrm{m}$ diam.

Tubes - Generative hyphae frequent, thin-walled, rarely branched, usually covered by fine, sharp-pointed encrustations, especially at dissepiment edge, 2-3 $\mu \mathrm{m}$ diam; skeletal hyphae dominant at upper part of tube, thick-walled with a narrow lumen to subsolid, unbranched, interwoven, agglutinated, 2.5-3.5 $\mu \mathrm{m}$ diam. Dissepiment edge with scanty smooth skeletal hyphae and abundant, spirally winding, encrusted generative hyphae. Cystidia absent; cystidioles abundant, spindle-shaped to almond-shaped, with a conical apex or rudimentary neck, almost as size as basidia, $8-10 \times 3-4 \mu \mathrm{m}$. Basidia broadly clavate to barrel-shaped, with a basal clamp connection and four sterigmata, 7-9 $\times 4-5 \mu \mathrm{m}$; basidioles in shape similar to basidia, but slightly smaller. 
Spores - Basidiospores mostly allantoid, hyaline, thin-walled, smooth, with one or two guttules, CB-, IKI-, (3.9-)4-5(-5.7 ) $\times(0.9-) 1.0-1.1(-1.2) \mu \mathrm{m}, \mathrm{L}=4.43 \mu \mathrm{m}, \mathrm{W}=1.06 \mu \mathrm{m}, \mathrm{Q}=$ $4.18(\mathrm{n}=30 / 1)$.

Notes - Skeletocutis pseudo-odora is characterized by resupinate, snow white pores when fresh, but brownish buff when dry, distinct byssoid to cottony sterile margin, circular pores mostly 6-8 per mm with entire mouths, a dimitic hyphal structure in subiculum and upper part of tube, generative hyphae in trama covered by fine crystals, skeletal hyphae unchanged in $\mathrm{KOH}$, allantoid basidiospores which measure 3.5-4.5 × 1.0-1.2 $\mu \mathrm{m}$, and growing on pine wood.

Additional specimens examined (Paratypes) - CHINA, Guizhou Province, Leishan County, Leigongshan Nature Reserve, on fallen branch of Pinus armandii, alt. 1800 m, 13 June 2016, Y.C.

Dai 16520 (BJFC022512), 16528 (BJFC022514), 16534 (BJFC022515).

\section{Key to species of Skeletocutis in China}

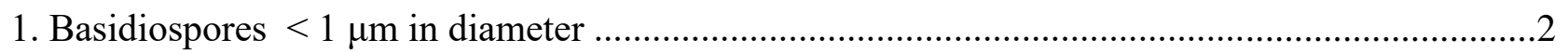

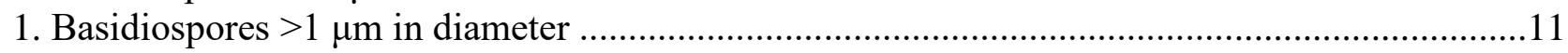

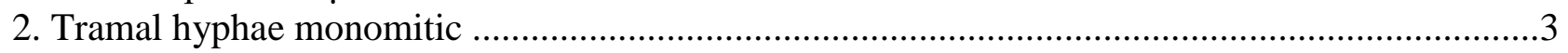

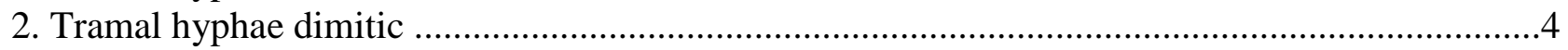

3. Growing on angiosperms; pore surface usually with bluish-grey tint ............................... nivea

3. Growing on gymnosperms; pore surface with salmon or amber tint ........................... S. ochroalba

4. Basidiocarps with fimbriate to rhizomorphic margin ............................................... fimbriata

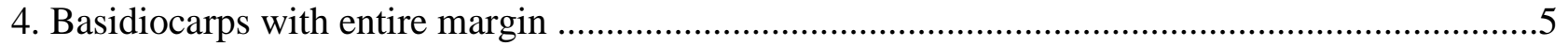

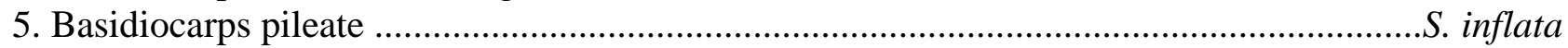



6. Pore surface violaceous ................................................................................................... lilacina

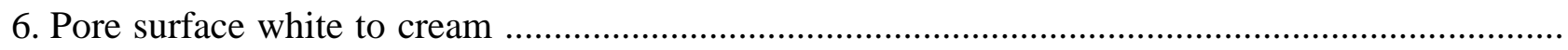



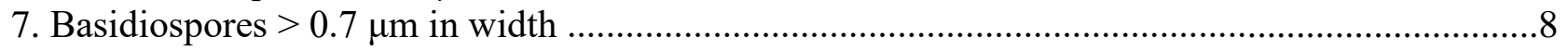

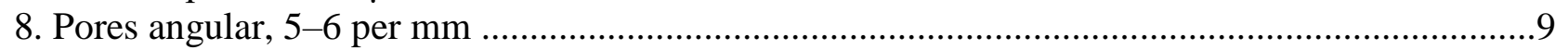

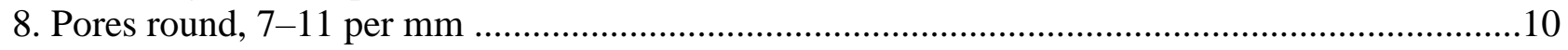

9. Basidiocarps thin, fragile; accompanying Trichaptum species .................................... kuehneri

9. Basidiocarps sturdy, tough; accompanying Phellinus species .................................... ch. chrysella

10. Basidiocarps perennial; skeletal hyphae unchanged in $\mathrm{KOH}$........................................S. stellae

10. Basidiocarps annual; skeletal hyphae swollen in $\mathrm{KOH}$.............................................S. substellae

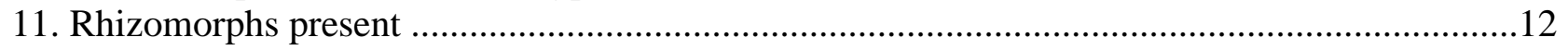

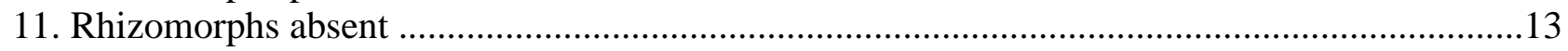



12. Basidiospores $>5 \mu \mathrm{m}$ in length ......................................................................... percandida

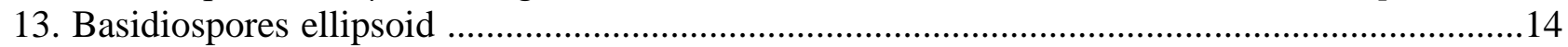

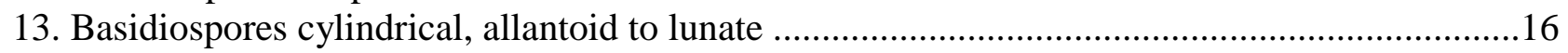

14. Growing on bamboo; pores 8-11 per $\mathrm{mm}$......................................................... bambusicola

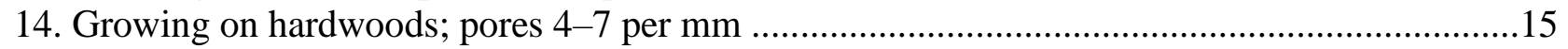

15. Basidiocarps perennial; basidiospores $<2.5 \mu \mathrm{m}$ in width ............................................ perennis

15. Basidiocarps annual; basidiospores $>2.5 \mu \mathrm{m}$ in width ............................................ sensitive





17. Fresh pores orange; basidiospores $>1.3 \mu \mathrm{m}$ in width ............................................... amorpha

17. Fresh pores pinkish grey; basidiospores $<1.3 \mu \mathrm{m}$ in width .................................. carneogrisea

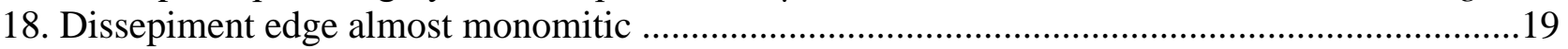

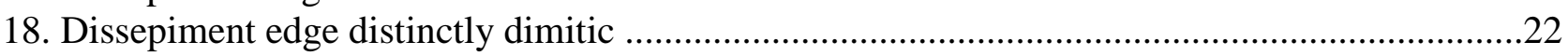

19. Basidiocarps thick and fleshy, with odor when fresh ................................................... odora

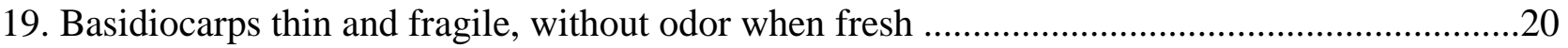


21. Pores mostly 5-6 per mm; generative hyphae in subiculum and trama covered by fine crystals S. yunnanensis

21. Pores mostly 6-8 per $\mathrm{mm}$, generative hyphae in trama covered by fine crystals ....S. albocremea

22. Basidiospores curved .23

22. Basidiospores fairly straight 24

23. Pore surface lemon yellow when dry; accompanying Phellinidium species S. brevispora

23. Pore surface yellowish cream when dry; on rotten Pinus wood S. subvulgaris

24. Skeletal hyphae unchanged in $\mathrm{KOH}$ S. biguttulata 24. Skeletal hyphae dissolved in $\mathrm{KOH}$ S. papyracea

\section{Discussion}

Skeletocutis pseudo-odora is characterized by resupinate basidiocarp with distinct sterile margin, snow white poroid surface when fresh which becomes brownish buff when dry, small pores (6-8 per $\mathrm{mm}$ ) with entire dissepiments, a dimitic hyphal structure with encrusted generative hyphae at tube trama only, cylindrical to allantoid basidiospores $(4-5 \times 1-1.1 \mu \mathrm{m})$, and growing on fallen wood of Pinus.

Macro-morphologically Skeletocutis pseudo-odora resembles S. albocream A. David by having thin basidiocarp with very thin subiculum, distinct, byssoid to cottony margin, similar pores (6-8 per $\mathrm{mm}$ ) and entire pore mouths. However, $S$. albocream has frequent hyphal pegs, dominant generative hyphae in subiculum, thicker basidiospores $(4-5 \times 1.3-1.7 \mu \mathrm{m}$, Niemelä 1998); while $S$. pseudo-odora lacks hyphal pegs, its skeletal hyphae are dominant in subiculum, basidiospores are thinner $(4-5 \times 1-1.1 \mu \mathrm{m})$.

Microscopically Skeletocutis odora is very similar to Skeletocutis pseudo-odora, and both species occur on gymnosperm wood. In fact the latter comes to the former when identifying our specimens follow the key by Niemelä (1998). However, S. odora has soft, juicy and acidic smell fresh basidiocarp, bigger pores (4-6 per $\mathrm{mm}$ ), thin and lacerate dissepiments. In contrast, $S$. pseudo-odora has corky fresh basidiocarp without any odour or taste, smaller pores (6-8 per $\mathrm{mm}$ ), thick and entire dissepiments.

Skeletocutis yunnanensis L.S. Bian, C.L. Zhao \& F. Wu was recently described from China (Bian et al. 2016), and it is similar to S. odora in having resupinate and white hymenophores and allantoid basidiospores $(3.5-4.5 \times 1-1.2 \mu \mathrm{m})$, but the former lacks sterile margin when mature, has bigger and angular pores (5-6 per $\mathrm{mm}$ ), its generative hyphae in subiculum and trama are covered by fine crystals, and grows on angiosperm wood (Bian et al. 2016).

Phylogenetically, the currently accepted species of Skeletocutis did not clustered into a wellsupported clade and $S$. pseudo-odora was not closely related to $S$. amorpha, the generic type (Fig. 1). However, according to morphological concept, we place S. pseudo-odora in Skeletocutis for now. Obviously, a combination of morphological examinations on more samples of Skeletocutis and comprehensive phylogenetic analysis with the aid of multiloci is needed to construct the phylogenetic framework for Skeletocutis.

Southwest China is very rich biodiversity (Yang 2010, Li et al. 2011). Although Guizhou located in southwest China, is a mountainous province, but more new fungal taxa, including species of Skeletocutis (Zhou \& Qin 2012, Bian et al. 2016), were found in Yunnan Province, the neighbor of Guizhou Province, e.g. more than 20 wood-decaying fungal species have been described from Yunnan during last ten years (Dai et al. 2007, 2009, Yuan \& Dai 2008, He \& Li 2011, 2013, Zhou \& Dai 2012, Tian et al. 2013, Jia et al. 2014, Li et al. 2014, Zhou 2014, Zhao et al. 2015, Zhou 2015, Zhou et al. 2016), but very few new taxa were found from Guizhou Province (Wu et al. 2015, Zhou 2016). One reason is that Guizhou has the Karst landform, and its vegetation is less rich for species than that in Yunnan Province. Another reason may be less investigation and study on mycota in Guizhou, and the fungal diversity in the area is still not well known. 



Fig. 2 - A basidiocarps of Skeletocutis pseudo-odora, Dai 16534 (BJFC022515). - Bar: $1 \mathrm{~cm}$.

Fig.3 - Microscopic structures of pseudo-odora (Holotype). a Basidiospores. b Basidioles. c Basidia. d Cystidioles. e A section from tube trama. f Hyphae from subiculum. Scale bars: $a=5$ $\mu \mathrm{m} ; \mathrm{b}-\mathrm{f}=10 \mu \mathrm{m}$.

\section{Acknowledgements}

We express our gratitude to Prof. Yu-Cheng Dai (BJFC, China) allowed us to study his specimens and to Miss Xiao-Hong Ji (BJFC, China) who helped in the preparation of the drawing. The research is supported by the Fundamental Research Funds for the Central Universities (Project Nos. 2016ZCQ04).

\section{References}

Bian LS, Zhao CL, Wu F. 2016 - A new species of Skeletocutis (Polyporales, Basidiomycota) from Yunnan of China. Phytotaxa 270, 267-276.

Binder M, Justo A, Riley R, Salamov A, López-Giráldez F, Sjökvist E, Copeland A, Foster B, Sun H, Larsson E, Larsson KH, Townsend J, Grigoriev IV, Hibbett DS. 2013 - Phylogenetic and phylogenomic overview of the Polyporales. Mycologia 105, 1350-1373.

Chen JJ, Cui BK, Dai YC. 2016 - Global diversity and molecular systematics of Wrightoporia s.l. (Russulales, Basidiomycota). Persoonia 37, 21-36.

Dai YC, Cui BK, Yuan HS. 2009 - Trichaptum (Basidiomycota, Hymenochaetales) from China with a description of three new species. Mycological Progress 8, 281-287.

Dai YC, Niemelä T, Kinnunen J, 2002 - The polypore genera Abundisporus and Perenniporia (Basidiomycota) in China, with notes on Haploporus. Ann. Bot. Fennici 39, 169-182.

Dai YC, Wu SH. 2004 - Megasporoporia (Aphyllophorales, Basidiomycota) in China. Mycotaxon 89, 379-388.

Dai YC, Yu CJ, Wang HC. 2007 - Polypores from eastern Xizang (Tibet), western China. Annales Botanicci Fennici 44, 135-145.

Dai YC. 2010 - Hymenochaetaceae (Basidiomycota) in China. Fungal Diversity 45, 131-343. 
Dai YC. 2012 - Polypore diversity in China with an annotated checklist of Chinese polypores. Mycoscience 53, 49-80.

Felsenstein J. 1985 - Confidence intervals on phylogenetics: an approach using bootstrap. Evolution 39, 783-791.

Gilbertson RL, Ryvarden L. 1987 - North American polypores Vol.2. MegasporoporiaWrightoporia. Mycologia 81, 437-885.

$\mathrm{He} \mathrm{SH}, \mathrm{Li}$ HJ. 2011 - Hymenochaete rhododendricola and H. quercicola spp. nov. (Basidiomycota, Hymenochaetales) from Tibet, southwestern China. Nordic Journal of Botany 29, 484-487.

He SH, Li HJ. 2013 - Pseudochaete latesetosa and P. subrigidula spp. nov (Hymenochaetales, Basidiomycota) from China based on morphological and molecular characters. Mycological Progress 12, 331-339.

Jia BS, Zhou LW, Cui BK, Rivoire B, Dai YC. 2014 - Taxonomy and phylogeny of Ceriporia (Polyporales, Basidiomycota) with an emphasis of Chinese collections. Mycological Progress 13, 81-93.

Katoh K, Kuma KI, Toh H, Miyata T. 2005 - MAFFT version 5: improvement in accuracy of multiple sequence alignment. Nucleic Acids Research 33, 511-518.

Katoh K, Standley DM. 2013 - MAFFT multiple sequence alignment software version 7: improvements in performance and usability. Molecular Biology and Evolution 30, 772-780.

Kotlába F, Pouzar Z. 1958 - Polypori novi vel minus cogniti Cechoslovakiae 3. Ceská Myk ologie $12,95-104$.

Li HJ, Cui BK, Dai YC. 2014 - Taxonomy and multi-gene phylogeny of Datronia (Polyporales, Basidiomycota). Persoonia 32, 170-182.

Li YC, Feng B, Yang ZL. 2011 - Zangia, a new genus of Boletaceae supported by molecular and morphological evidence. Fungal Diversity 49, 125-143.

Niemelä T. 1998 - The Skeletocutis subincarnata complex (Basidiomycetes), a revision. Acta Botanica Fennica 161, 1-35.

Pattengale ND, Alipour M, Bininda-Emonds ORP, Moret BME, Stamatakis A. 2010 - How many bootstrap replicates are necessary? Journal of Computational Biology 17, 337-354.

Petersen JH. 1996 - Farvekort. The Danish Mycological Society's colour-chart. Foreningen til Svampekundskabens Fremme, Greve. . 1-6.

Ryvarden L, Melo I. 2014 - Poroid fungi of Europe. Synopsis Fungorum 31, 1-455.

Silvestro D, Michalak I. 2012 - raxmlGUI: a graphical front-end for RAxML. Organisms Diversity and Evolution 12, 335-337.

Stamatakis A. 2006 - RAxML-VI-HPC: maximum likelihood-based phylogenetic analyses with thousands of taxa and mixed models. Bioinformatics 22, 2688-2690.

Swofford DL. 2002 - PAUP*: phylogenetic analysis using parsimony (*and other methods), version 4.0b10. Sinauer Associates, Sunderland.

Tian XM, Yu HY, Zhou LW, Decock C, Vlasák J, Dai YC. 2013 - Phylogeny and taxonomy of the Inonotus linteus complex. Fungal Diversity 58, 159-169.

Wu F, Yang J, Zhou LW. 2015 - Mensularia rhododendri (Hymenochaetaceae, Basidiomycota) from southwestern China. Phytotaxa 212, 157-162.

Yang ZL. 2010 - Inventory of higher fungi in the Hengduan Mountains of southwestern China. Chinese Bulletin of Life Sciences 22, 1086-1091.

Yuan HS, Dai YC. 2008 - Polypores from northern and central Yunnan Province, Southwestern China. Sydowia 60, 147-159.

Zhao CL, Cui BK, Song J, Dai YC. 2015 - Fragiliporiaceae, a new family of Polyporales (Basidiomycota). Fungal Diversity 70, 115-126.

Zhou LW, Dai YC. 2012 - Phylogeny and taxonomy of Phylloporia (Hymenochaetales) with the description of five new species and a key to worldwide species. Mycologia 104, 211-222.

Zhou LW, Qin WM. 2012 - A new species of Skeletocutis (Polyporaceae) on bamboo in tropical China. Mycotaxon 119, 345-350. 
Zhou LW, Vlasák J, Qin WM, Dai YC. 2016 - Global diversity and phylogeny of the Phellinus igniarius complex (Hymenochaetales, Basidiomycota) with the description of five new species. Mycologia 108, 192-204.

Zhou LW. 2014 - Mensularia lithocarpi sp. nov. from Yunnan Province, southwestern China. Mycotaxon 127, 103-109.

Zhou LW. 2015 - Phellinopsis asetosa sp. nov. (Hymenochaetales, Basidiomycota) and an emended circumscription of Phellinopsis with a key to accepted species. Mycoscience 56, 237-242.

Zhou LW. 2016 - Phylloporia minutipora and P. radiata spp. nov. (Hymenochaetales, Basidiomycota) from China and a key to worldwide species of Phylloporia. Mycological Progress 15, 57. 